\title{
Should low birth-weight be considered a relevant risk factor for rise in pulse pressure among adult overweight-obese subjects?
}

\author{
Anna Fedi, ${ }^{1}$ Franco Cipollini, ${ }^{1}$ Enrica Arcangeli, ${ }^{1}$ Gianna Fabbri, ${ }^{2}$ Laura Policardo, ${ }^{3}$ Marta Seghieri, ${ }^{4}$ Giuseppe Seghieri ${ }^{3}$ \\ ${ }^{1}$ Hypertension Unit, Department of Internal Medicine, S. Jacopo Hospital, Pistoia; ${ }^{2}$ Dietetic Outpatient Clinic, S. Jacopo Hospital, \\ Pistoia; ${ }^{3}$ Tuscan Regional Health Agency, Florence; ${ }^{4}$ General Medicine II, Pisa University Medical School, Pisa, Italy
}

\begin{abstract}
Low birth-weight (BW) is related to rise in blood pressure (BP) later in life. Aim of this study is investigating whether presence of overweight-obesity modifies this relationship, independently from any additional correlate of metabolic syndrome. We studied $535\left(216 \mathrm{M} / 319 \mathrm{~F}\right.$ ) otherwise healthy overweight-obese people (body mass index $\geq 25 \mathrm{~kg} / \mathrm{m}^{2}$ ), recording systolic, diastolic and pulse BP as well as plasma glucose and lipids, additionally interviewing them about BW and weight-change after age of 18 years. The reciprocal of $\mathrm{BW}$ was related only to pulse pressure ( $\mathrm{PP}, \mathrm{r}=0.14 ; \mathrm{P}=0.04$ ), uniquely in men and individuals with $\mathrm{BW} \leq 2500 \mathrm{~g}$ had a higher relative risk of having PP above upper quartile ( $>60 \mathrm{mmHg})$, independently of sex. After adjusting for confounders each $1 \mathrm{~kg}$ rise in $\mathrm{BW}$ was associated with $2.84 \pm 0.88$ (standard error) $\mathrm{mmHg}$ decrease in PP; $\mathrm{P}=0.0042$. Moreover, again only among males, the lower BW the higher was the risk of a $\mathrm{PP}>60 \mathrm{mmHg}$ [odds ratio ( $95 \%$ confidence interval): 2.43 (1.39-4.24); $\mathrm{P}=0.0018$ ]. In conclusion $\mathrm{BW}$ was inversely related only with $\mathrm{PP}$ in overweight-obese subjects, uniquely in men, being such effect independent from other correlates of metabolic syndrome. Since elevated PP can be considered a proxy of vascular damage, these findings further stress the importance of inquiring about BW to better stratify the risk of vascular damage, in adult overweight-obese individuals.
\end{abstract}

\section{Introduction}

Several studies, published during the last couple of decades, have clearly demonstrated that low birthweight (BW) is a significant predictor of diabetes mel-

Correspondence: Giuseppe Seghieri, Tuscan Regional Health Agency, via Pietro Dazzi 1, 50141 Florence, Italy. Tel.: +39.338.6941642. E-mail: gseghier@tin.it

Key words: Low birth-weight; blood pressure; pulse pressure; obesity-overweight; relative risk; male gender.

Contributions: AF, GS, FC, EA conceived and designed the study; GF, MS extracted records and controlled the quality of the dataset; GS, LP discussed and edited the manuscript; GS, guarantor of this paper, had full access to all the data in the study and takes the responsibility for the integrity of data and accuracy of data analysis.

Conference: part of this study has been presented at the $23^{\text {rd }}$ European Meeting of Hypertension and Cardiovascular Protection, 24-27 June 2013, Milan, Italy.

Conflict of interest: the authors declare no potential conflict of interest.

Received for publication: 7 November 2014.

Accepted for publication: 18 November 2014.

This work is licensed under a Creative Commons Attribution NonCommercial 3.0 License (CC BY-NC 3.0).

CCopyright A. Fedi et al., 2015

Licensee PAGEPress, Italy

Italian Journal of Medicine 2015; 9:273-278

doi:10.4081/itjm.2015.559 litus, hypertension or metabolic syndrome later in life. ${ }^{1-8}$ Among correlates of metabolic syndrome obesity seems, however, to be an exception since the majority of studies has pointed out that there is a direct, instead of an inverse, relationship between BW and obesity in children, adolescents or even in adults. ${ }^{9}$ The consequence of this, in the light of the strict link existing between obesity and arterial hypertension, is that in obese subjects an attenuated or even a reversed relation between a small $\mathrm{BW}$ and raised blood pressure (BP) in adult life may be expected.

In addition, all meta-analyses concerning either case control or population studies, have not been able to clearly ascertain what type of blood pressure (systolic, diastolic or pulse $\mathrm{BP}$ ) was more related to low $\mathrm{BW}$, as well as whether this is observed in overweight-obese subjects independently from the frequently associated correlates of hypertension or metabolic syndrome (altered glucose metabolism, rise in plasma lipids, increase in body weight during the adult life, etc.). Furthermore a poorly investigated point is the effect exerted by change in body weight in age beyond 18 years on raised levels of blood pressure, since the majority of previous studies regard only females. ${ }^{10-12}$ Finally, a further question which has not yet been completely clarified is whether the relationship between low BW and rise in $\mathrm{BP}$ is equally present in men and in women.

This study is aimed at answering each of these questions, by retrospectively reviewing the database of overweight-obese patients who came to our hospital's outpatient clinic asking for dietetic advice. 


\section{Materials and Methods}

\section{Patients}

This study presents the results obtained by the retrospective analysis of a dataset concerning 535 overweight-obese people [body mass index (BMI) $\geq 25$ $\left.\mathrm{kg} / \mathrm{m}^{2}\right], 216$ males, and 319 females, otherwise healthy, who consecutively came to the dietetic outpatient clinic of our hospital to obtain dietetic advice, during the last four years, sent by their family practitioners.

\section{Methods}

In all patients we recorded BMI (body weight in kilograms divided by the square of the height in meters), waist circumference (recorded as centimetres at the upper hip bone by a measuring tape around the abdomen), and fasting plasma concentration of glucose or lipids, by standardized methods. BW was ascertained by means of a standardized interview as previously described, ${ }^{13}$ additionally inquiring about body weight value at the approximate age of 18 years, recorded as the ratio of the difference between actual and recalled weight at age of 18 ( $\Delta$-weight at numerator), to actual age subtracting 18 at denominator $[\Delta$ weight/age-18; $(\mathrm{kg} / \mathrm{y})]$.

BW was considered as a continuous variable or categorized by two classes ( $\leq 2500 \mathrm{~g}$ or $>2500 \mathrm{~g}$ ).

In each patient office blood pressure was recorded as the mean of three measurements obtained in the sitting position, using suitable cuffs for obese people $(12 \times 40 \mathrm{~cm}) .^{14}$

This study has been approved by the Ethical Committee of our Hospital.

\section{Statistics}

Univariate statistics included comparisons between male and female subjects or between those with BW $\leq 2500 \mathrm{~g}$ and those $>2500 \mathrm{~g}$ by 2 -tailed-Wilcoxonrank-sums test. Spearman's coefficients after leastsquares method were used to evaluate correlations among continuous variables, and, in this same analysis BW was transformed into its reciprocal to normalize the distribution.

Relative risks according to $\mathrm{BW} \leq$ or $>2500 \mathrm{~g}$, separately evaluated by sex, were calculated with the Mantel-Haenszel method after Chi-square test.

Stepwise multivariate regression analysis, was used to evaluate the hierarchy of independent variables in building up the total BP variance (systolic, diastolic, and pulse pressure) by a model where BP was the dependent variable and age, BMI, waist circumference, $\Delta$-weight/age, total cholesterol, triglycerides, fasting plasma glucose and high-density lipoproteincholesterol entered the model as covariates. The assumed significance level for variables entering into the model was 0.15 .
A multiple logistic regression analysis was carried out to assess the adjusted relative risk of elevated BP values: according to this model the dependent variables (y) were, alternatively, systolic, diastolic or pulse pressure stratified as under or above their upper quartile and expressed as dummies 0 and 1 . Independent variables were age, BMI, waist circumference, $\Delta$ weight/age, and BW introduced as a continuous variable or alternatively categorized as $\leq 2500$ (dummy $=0$ ) or $>2500$ g (dummy $=1)$.

Significance of P-value was set at $<0.05$. All statistical analyses were carried out by means of SAS software for Windows, version 9.3 (SAS Institute Inc., Cary, NC, USA).

\section{Results}

The main characteristics of population stratified by sex are reported in Table 1. Prevalence of smokers was higher among males, who were moreover characterized by a greater $\Delta$-weight/age, as well as by a larger waist circumference and increased prevalence of dyslipidemia. BW was, as expected, on average, higher among males while, conversely, the prevalence rate of small babies (BW $\leq 2500 \mathrm{~g}$ ) was lower in men than in women. With regard to BP values, only systolic BP, on average higher among males, was significantly different between genders (Table 1).

In univariate analysis the reciprocal value of BW was not related to any of the measured variables, except for a weak relation with pulse pressure, among males ( $\mathrm{r}=0.14$; $\mathrm{P}=0.04$; Table 2).

While mean diastolic and systolic BP were not significantly different between those with BW above or under $2500 \mathrm{~g}$, pulse pressure, defined as the difference between systolic and diastolic BP, was significantly higher in the group with $\mathrm{BW} \leq 2500 \mathrm{~g}$ in men $(58 \pm 11$ standard deviation $\mathrm{mmHg}$ vs $51 \pm 13 \mathrm{mmHg}$; $\mathrm{P}=0.012$ by Wilcoxon rank sums test), not among the women ( $52 \pm 15 \mathrm{mmHg}$ vs $48 \pm 14 \mathrm{mmHg}$; $\mathrm{P}=$ not significant). Pulse pressure resulted significantly higher in women with $\mathrm{BW} \leq 2000 \mathrm{~g}(\mathrm{n}=18 ; 5.6 \%)$ compared to those above this cut-off $(57 \pm 17 \mathrm{mmHg}$ vs $49 \pm 14 \mathrm{mmHg}$; $\mathrm{P}=0.0192$ ). In addition, the relative risk of having a pulse pressure exceeding its upper quartile $(>60$ $\mathrm{mmHg}$ ) was significantly higher in those with BW $\leq 2500 \mathrm{~g}$ both in men and women, while, contrarily, a lower BW was not associated with the rise in relative risk of having a systolic or diastolic BP exceeding their upper quartile $(>150 \mathrm{mmHg}$ for systolic and $>95$ $\mathrm{mmHg}$ for diastolic BP) (Table 3).

Only pulse pressure elevation was significantly and independently associated with a low BW in men, independently from any of the main constituents clustering metabolic syndrome (waist circumference, increase in plasma glucose and lipids, BMI) (Table 4). 
From this same model, among men, each $1 \mathrm{~kg}$ rise in $\mathrm{BW}$, after adjusting for covariates, was associated with a decrease of $2.84 \pm 0.88$ (standard error) $\mathrm{mmHg}$ in pulse pressure; $\mathrm{P}=0.0042$.

The relative risk, expressed as odds ratio (OR), of having a BP in the upper quartile of systolic, diastolic and pulse pressure, according to each $\mathrm{kg}$ decrease in $\mathrm{BW}$, after adjusting for BMI, age, past weight increase, blood glucose and plasma lipids is shown in Figure 1. While the adjusted relative risk was not sig- nificant for systolic and diastolic BP, the OR of having pulse pressure $>60 \mathrm{mmHg}$ was significantly higher only among men, rising by about 2.5 fold for each $\mathrm{kg}$ decrease in BW [OR (95\% confidence interval, $\mathrm{CI})$ : 2.43 (139-4.24); $\mathrm{P}=0.0018]$. Similar results were obtained replacing $\mathrm{BW}$ with its categorical measures $\leq$ or $>2500 \mathrm{~g}$ (data not shown).

No significant associations were observed between small BW and the presence of arterial hypertension defined as systolic $\mathrm{BP}>140 \mathrm{mmHg}$ and/or diastolic $\mathrm{BP}>90$

Table 1. Characteristics of patients under study [mean \pm standard deviation or median (interquartile range)].

\begin{tabular}{|c|c|c|c|}
\hline & Males & Females & P value \\
\hline No. & 216 & 319 & - \\
\hline Age $(y)$ & $42 \pm 15$ & $43 \pm 14$ & ns \\
\hline Menopause (\%) & - & $103(19.2)$ & - \\
\hline Smokers $(\%)$ & 35 & 25 & 0.02 \\
\hline BMI $\left(\mathrm{kg} / \mathrm{m}^{2}\right)$ & $32 \pm 4.5$ & $31.2 \pm 5.7$ & ns \\
\hline BMI at 18 years $\left(\mathrm{kg} / \mathrm{m}^{2}\right)$ & $24.2 \pm 3.9$ & $22.9 \pm 3.7$ & 0.02 \\
\hline$\Delta$-weight/age $(\mathrm{kg} / \mathrm{y})^{*}$ & $1.00(1.08)$ & $0.87(0.78)$ & 0.02 \\
\hline Waist circumference $(\mathrm{cm})$ & $108 \pm 11$ & $98.6 \pm 12.9$ & 0.0001 \\
\hline Systolic blood pressure (mmHg) & $140 \pm 17$ & $135 \pm 20$ & 0.02 \\
\hline Diastolic blood pressure $(\mathrm{mmHg})$ & $89 \pm 10$ & $86 \pm 11$ & ns \\
\hline Pulse pressure $(\mathrm{mmHg})^{\circ}$ & $51 \pm 13$ & $49 \pm 14$ & ns \\
\hline Fasting plasma glucose $(\mathrm{mg} / 100 \mathrm{~mL})$ & $97 \pm 17$ & $94 \pm 16$ & ns \\
\hline Plasma cholesterol (mg/100 mL) & $213 \pm 40$ & $212 \pm 43$ & ns \\
\hline Plasma triglycerides $(\mathrm{mg} / 100 \mathrm{~mL})$ & $183 \pm 110$ & $124 \pm 67$ & 0.0001 \\
\hline HDL cholesterol (mg/100 mL) & $43 \pm 11$ & $55 \pm 13$ & 0.0001 \\
\hline Birth-weight (g) & $3757 \pm 866$ & $3343 \pm 793$ & 0.0001 \\
\hline No. $(\%)$ of small babies $(\leq 2500 \mathrm{~g})$ & $14(6.5)$ & $40(12.5)$ & 0.02 \\
\hline
\end{tabular}

Table 2. Univariate correlations with the reciprocal of birth-weight, in males and females.

\begin{tabular}{|c|c|c|c|c|}
\hline & \multicolumn{2}{|c|}{ Males } & \multicolumn{2}{|c|}{ Females } \\
\hline & $\mathbf{r}$ & P value & $\mathbf{r}$ & P value \\
\hline BMI & -0.09 & ns & -0.004 & ns \\
\hline Weight circumference & -0.08 & ns & 0.01 & ns \\
\hline$\Delta$-weight* & -0.009 & ns & 0.004 & ns \\
\hline Systolic blood pressure & 0.04 & ns & 0.06 & ns \\
\hline Diastolic blood pressure & -0.09 & ns & -0.006 & ns \\
\hline Pulse pressure & 0.14 & 0.04 & 0.10 & ns \\
\hline Plasma fasting glucose & 0.11 & ns & 0.05 & ns \\
\hline Triglycerides & -0.08 & ns & 0.06 & ns \\
\hline Cholesterol & 0.05 & ns & 0.13 & 0.02 \\
\hline HDL cholesterol & 0.05 & ns & 0.03 & ns \\
\hline
\end{tabular}

BMI, body mass index; ns, not significant; HDL, high-density lipoprotein. *Weight increase since age of 18 years. 
$\mathrm{mmHg}$, both in univariate and multivariate analyses.

Finally no differences, in systolic, diastolic or pulse pressure were observed after stratifying BW as $<$ or $\geq 4000 \mathrm{~g}$ (data not shown).

\section{Discussion and Conclusions}

A small BW is a major risk factor for development of increased BP values later in adult life ${ }^{15-19}$ as stressed by a recently published meta-analysis, which has moreover evidenced that BW is inversely related to systolic and to a lesser extent to diastolic BP in a linear way estimating that $1 \mathrm{~kg}$ increase in BW is associated with 2$4 \mathrm{mmHg}$ reduction in systolic BP. ${ }^{7}$ Moreover several evidences have been accrued in the past, unanimously highlighting that a small $\mathrm{BW}$, as observed in preterm births, is associated with the development of arterial hypertension later, even in children or in adolescents. ${ }^{1,20}$

The reason of this inverse relation between small BW and increased BP has yet not been fully clarified, suggesting that a growth retardation in utero may lead to a significantly greater risk for the development of the cluster of metabolic syndrome's correlates (diabetes, hypertension, dyslipidemia, obesity) and, consequently, to the risk of any among the associated cardiovascular events, later in the adult life. ${ }^{21}$

Furthermore, since hypertension and obesity may frequently occur together, we guessed being of interest to study whether the increased risk conferred by a low BW is being equally present in overweight-obese people. This latter aspect has not fully been addressed by previous studies since the majority of them have calculated the risks simply after adjusting for body weight, and the issue is moreover more complicated by the fact that, contrarily, a high BW seems to predict a raised risk for development of obesity later in adult life, ${ }^{9}$ so partially dampening the expected inverse relation of BW with high blood pressure. A second point which has, till now, scarcely been investigated is whether sex may modify the relation between small $\mathrm{BW}$ with risk and increased BP in the adult life.

Table 3. Unadjusted relative risks ( $95 \%$ confidence interval) by Mantel-Haenszel method after Chi-square test of having systolic, diastolic or pulse pressure in the upper quartile according to birth-weight class $\leq$ or $>2500 \mathrm{~g}$, in males and in females.

\begin{tabular}{|c|c|c|c|c|c|c|c|c|}
\hline & \multicolumn{4}{|c|}{ Males } & \multicolumn{4}{|c|}{ Females } \\
\hline & \multicolumn{2}{|c|}{ Birth-weight } & \multirow{2}{*}{$\begin{array}{l}\text { Relative risk } \\
(95 \% \text { CI })\end{array}$} & \multirow{2}{*}{ P value } & \multicolumn{2}{|c|}{ Birth-weight } & \multirow{2}{*}{$\begin{array}{l}\text { Relative risk } \\
\text { (95\% CI) }\end{array}$} & \multirow[t]{2}{*}{ P value } \\
\hline & $\leq 2500 \mathrm{~g}$ & $>2500 \mathrm{~g}$ & & & $\leq 2500 \mathrm{~g}$ & $>2500 \mathrm{~g}$ & & \\
\hline $\begin{array}{l}\text { Subjects in upper } \\
\text { PP quartile }(>60 \mathrm{mmHg})\end{array}$ & $\begin{array}{c}9 / 63 \\
(14.3)\end{array}$ & $\begin{array}{l}5 / 153 \\
(3.3)\end{array}$ & $\begin{array}{c}2.1 \\
(1.1-4.2)\end{array}$ & 0.002 & $\begin{array}{l}17 / 83 \\
(20.5)\end{array}$ & $\begin{array}{c}23 / 236 \\
(9.7)\end{array}$ & $\begin{array}{c}1.33 \\
(1.1-1.7)\end{array}$ & 0.01 \\
\hline $\begin{array}{l}\text { Subjects in upper } \\
\text { DBP quartile ( }>95 \mathrm{mmHg})\end{array}$ & $\begin{array}{l}2 / 52 \\
(3.8)\end{array}$ & $\begin{array}{c}12 / 164 \\
(7.3)\end{array}$ & $\begin{array}{c}0.9 \\
(0.7-1.1)\end{array}$ & ns & $\begin{array}{c}8 / 54 \\
(14.8)\end{array}$ & $\begin{array}{l}32 / 265 \\
(12.1)\end{array}$ & $\begin{array}{c}1.1 \\
(0.9-1.3)\end{array}$ & ns \\
\hline $\begin{array}{l}\text { Subjects in upper } \\
\text { SBP quartile }(>150 \mathrm{mmHg})\end{array}$ & $\begin{array}{l}5 / 72 \\
(6.9)\end{array}$ & $\begin{array}{l}9 / 144 \\
(6.2)\end{array}$ & $\begin{array}{c}1.1 \\
(0.7-1.5)\end{array}$ & ns & $\begin{array}{l}11 / 84 \\
(13.1)\end{array}$ & $\begin{array}{l}29 / 235 \\
(12.3)\end{array}$ & $\begin{array}{c}1.1 \\
(0.8-1.2)\end{array}$ & ns \\
\hline
\end{tabular}

$\mathrm{CI}$, confidence interval; PP, pulse pressure; ns, not significant; DBP, diastolic pressure; SBP, systolic pressure.

Table 4. Stepwise regression analysis relating pulse, systolic, and diastolic blood pressure as dependent variables with reciprocal of birth-weight, body mass index, age, waist circumference, past weight increase, blood glucose, and plasma lipids as independent variables. The assumed significance level for variables entering into the model was 0.15 .

\begin{tabular}{|c|c|c|c|c|}
\hline \multirow[t]{2}{*}{ Variables } & \multicolumn{2}{|c|}{ Males } & \multicolumn{2}{|c|}{ Females } \\
\hline & Model R ${ }^{2}$ & $P$ value & Model R ${ }^{2}$ & P value \\
\hline \multicolumn{5}{|l|}{ Pulse pressure } \\
\hline Age & 0.054 & 0.0056 & 0.127 & 0.0001 \\
\hline BMI & 0.136 & 0.038 & 0.171 & 0.0023 \\
\hline Birth weight & 0.109 & 0.0042 & & \\
\hline \multicolumn{5}{|c|}{ Systolic blood pressure } \\
\hline Age & 0.080 & 0.0007 & 0.177 & 0.0001 \\
\hline BMI & 0.162 & 0.0003 & 0.255 & 0.0001 \\
\hline Triglycerides & 0.229 & 0.0008 & & \\
\hline Birth weight & 0.2511 & 0.0471 & & \\
\hline \multicolumn{5}{|c|}{ Diastolic blood pressure } \\
\hline Age & 0.211 & 0.0252 & 0.101 & 0.0001 \\
\hline BMI & 0.181 & 0.0007 & 0.164 & 0.0003 \\
\hline Triglycerides & 0.110 & 0.0001 & & \\
\hline
\end{tabular}

BMI, body mass index. 
As to the first point our findings suggest that only pulse pressure, uniquely among men, is linearly related to small $\mathrm{BW}$ in overweight-obese individuals. From a recent meta-analysis, evaluating a wide panel of studies, the mean difference in systolic BP between subjects with low BW $(<2500 \mathrm{~g})$ compared with subjects with $\mathrm{BW}>2500 \mathrm{~g}$ was $2.58 \mathrm{mmHg}(95 \% \mathrm{CI}$ 1.51-3.64), being the difference in diastolic BP, on average, much lower [1.01 $\mathrm{mmHg}(0.19-1.83)]$, while no data have been given about pulse pressure. ${ }^{7}$

In this context a previous study by Lurbe et al. ${ }^{22}$ showed that obesity magnifies the inverse relation between BW and BP in adolescents (mean age 13 year), even if in multivariate analysis this relation lost any significance for office $\mathrm{PP}(\mathrm{P}=0.165)$.

Since pulse pressure is the difference between systolic and diastolic BP it is not surprising that it may have a significant negative association with $\mathrm{BW}$. What is at variance with previous studies, however, is the lack of any inverse relation between systolic BP and $\mathrm{BW}$, and it can be hypothesized that this could represent a specific feature differentiating obese from nonobese individuals, even considering that comparisons with past studies are made difficult by the not homogeneous prevalence of overweight-obese individuals in each of them.

A further observation from our findings is that low $\mathrm{BW}$ was not associated with the risk of arterial hypertension defined as a $\mathrm{BP}>140 / 90 \mathrm{mmHg}$, at variance with what observed by previous population studies. ${ }^{23}$ This is probably due to the fact that cut-off values for hypertension may be more elevated in obese people even if, as also suggested by multivariate analysis; males have a weak association between low BW and upper systolic BP quartile (Table 4).

An additional support to the relation between pulse pressure and small BW is given by the fact that, in the

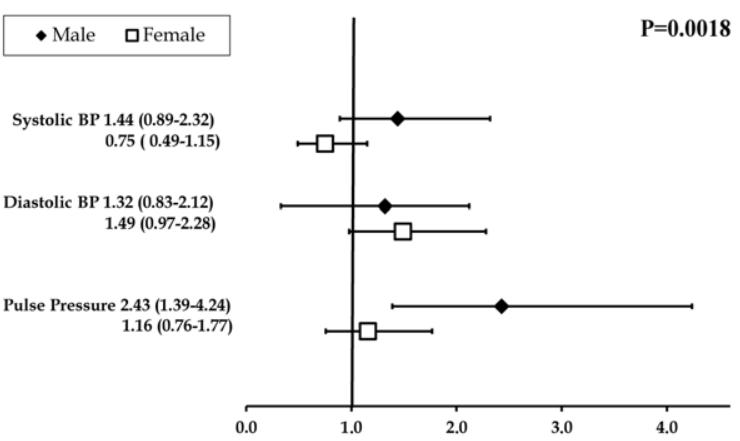

Figure 1. Risk of being in the upper quartile of systolic, diastolic or pulse blood pressure (BP), expressed as odds ratio (95\% confidence interval) according to each $\mathrm{kg}$ decrease in birth-weight, adjusted for body mass index, age, waist circumference, past weight increase, blood glucose, and plasma lipids in men and in women. elderly pulse pressure increases as the result of increased arterial stiffness ${ }^{24,25}$ and arterial rigidity, by whichever way measured, i.e., as stiffness index or arterial pulsatile function, has been demonstrated as being significantly related to small $\mathrm{BW}$, even at a much higher extent than systolic or diastolic BP..$^{26,27}$

The reason of sex dimorphism in the association low BW-pulse pressure is not clarified by our study. What appears from meta-analyses is that the inverse relation between BP and BW seems more evident in males $^{7}$ even if this is yet widely controversial. To the best of our knowledge neither previous studies, nor any meta-analysis, have been carried out with the primary purpose of answering this question. What is suggested by our data is that defining the lower cut-off threshold to categorize a small BW may be crucial also in the light of the observation that the rate of individuals with $\mathrm{BW} \leq 2500 \mathrm{~g}$ is significantly higher among women. In this regard, it is interesting to note that, from our data, mean pulse pressure resulted significantly higher in women with $\mathrm{BW} \leq 2000 \mathrm{~g}$, obtaining values close to what observed in men. A further issue to be considered is that in the age range of our study, centred on a mean value of about 43 years for both genders, the risk of arterial hypertension is greater among males ${ }^{28}$ and such an excess risk could contribute to the gender difference, which we observed.

A main point suggested by the present study is that among the clinical correlates of metabolic syndrome, none has, hierarchically, the same relevance presented by low BW in predicting raised pulse pressure in adult life. In other words, even in overweight-obese people, it seems opportune adding a low BW, when available, to the list of the risk factors able to eventually predict high pulse pressure, especially among men. The value expressed by mean change in body weight after age 18 , is, nonetheless, negligible in explaining the variance of adult BP.

This study has some limitations. A first limit is the way BW was recalled, namely by interview. This is, however a bias that is present in many of previous studies, and even if recording BW by a simple interview is obviously less sensitive than doing it by obstetrical records, it seems to be even more accurate than using a structured questionnaire, ${ }^{7}$ having, in addition, the advantage of being simple and immediate. A further related limitation is that information about gestational age as well as about more detailed measures of birth size is lacking.

\section{Conclusions}

Even if with the above mentioned limitations, this study confirms that also in overweight-obese subjects there is an inverse relationship between BW and increase in BP (pulse pressure), either considering BW 
as a continuous variable or after categorizing it as $\leq$ or $>2500 \mathrm{~g}$. The entire effect of BW on later increment in $\mathrm{BP}$ is, however, modest since $1 \mathrm{~kg}$ increase in $\mathrm{BW}$ is associated with a mean of $2.84 \mathrm{mmHg}$ reduction in pulse pressure, even if it seems hierarchically more important in predicting raised arterial stiffness than any other correlate of the metabolic syndrome.

The second conclusion to be drawn from our findings is that the relation between small $\mathrm{BW}$ and rise in pulse pressure is more evident among men, and that such sexual dimorphism is for the most part reversed after introducing for women a lower BW cut-off threshold (2000 g).

The third conclusion is that inquiring about weight change after adolescence is of poor significance in determining the risk of elevated BP values in our population of overweight-obese patients.

Since elevated pulse pressure can be considered a proxy of vascular damage, these findings further stress the importance of inquiring about BW to better stratify the risk of vascular damage, in adult life among overweight-obese individuals, especially in men.

\section{References}

1. de Jong F, Monuteaux MC, van Elburg RM, et al. Systematic review and meta-analysis of preterm birth and later systolic blood pressure. Hypertension 2012;59:226-34.

2. Andersson SW, Lapidus L, Niklasson A, et al. Blood pressure and hypertension in middle-aged women in relation to weight and length at birth: a follow-up study. J Hypertens 2000;18:1753-61.

3. Nilsson PM, Ostergren PO, Nyberg P, et al. Low birth weight is associated with elevated systolic blood pressure in adolescence: a prospective study of a birth cohort of 149378 Swedish boys. J Hypertens 1997;15:1627-31.

4. Harder T, Rodekamp E, Schellong K, et al. Birth weight and subsequent risk of type 2 diabetes: a meta-analysis. Am J Epidemiol 2007;165:849-57.

5. Law CM, Shiell AW. Is blood pressure inversely related to birth weight? The strength of evidence from a systematic review of the literature. J Hypertens 1996;14:935-41.

6. Tamakoshi K, Yatsuya H, Wada K, et al. Birth weight and adult hypertension: cross-sectional study in a Japanese workplace population. Circ J 2006;70:262-7.

7. Mu M, Wang SF, Sheng J, Zhao Y, et al. Birth weight and subsequent blood pressure: a meta-analysis. Arch Cardiovasc Dis 2012;105:99-113.

8. Phillips DI. Fetal programming of the neuroendocrine response to stress: links between low birth weight and the metabolic syndrome. Endocr Res 2004;30:819-26.

9. Yu ZB, Han SP, Zhu GZ, et al. Birth weight and subsequent risk of obesity: a systematic review and metaanalysis. Obes Rev 2011;12:525-42.

10. Yong LC, Kuller LH, Rutan G, et al. Longitudinal study of blood pressure: changes and determinants from adolescence to middle age. The Dormont High School Follow-up Study, 1957-1963 to 1989-1990. Am J Epidemiol 1993;138:973-83.
11. Field AE, Byers T, Hunter DJ, et al. Weight cycling, weight gain, and risk of hypertension in women. Am J Epidemiol 1999;150:573-9.

12. Huang Z, Willett WC, Manson JE, et al. Body weight, weight change, and risk for hypertension in women. Ann Intern Med 1998;128:81-8.

13. Seghieri G, Anichini R, De Bellis A, et al. Relationship between gestational diabetes mellitus and low maternal birth weight. Diabetes Care. 2002;25:1761-5.

14. Pickering TG, Hall JE, Appel LJ, et al. Recommendations for blood pressure measurement in human and experimental animals; part 1: blood pressure measurement in humans. A statement for professionals from the Subcommittee of Professional and Public Education of the American Heart Association Council on High Blood Pressure Research. Circulation 2005;111:697-716.

15. Järvelin MR, Sovio U, King V, et al. Early life factors and blood pressure at age 31 years in the 1966 northern Finland birth cohort. Hypertension 2004;44:838-46.

16. Kistner A, Celsi G, Vanpée M, et al. Increased systolic daily ambulatory blood pressure in adult women born preterm. Pediatr Nephrol 2005;20:232-3.

17. Yarbrough DE, Barrett-Connor E, Kritz-Silverstein D, et al. Birth weight, adult weight, and girth as predictors of the metabolic syndrome in postmenopausal women: the Rancho Bernardo Study. Diabetes Care 1998;21:1652-8.

18. Ylihärsilä H, Eriksson JG, Forsén T, et al. Self-perpetuating effects of birth size on blood pressure levels in elderly people. Hypertension 2003;41:446-50.

19. Huxley R, Neil A, Collins R. Unravelling the fetal origins hypothesis: is there really an inverse association between birthweight and subsequent blood pressure? Lancet 2002;360:659-65.

20. Keijzer-Veen MG, Dülger A, Dekker FW, et al. Very preterm birth is a risk factor for increased systolic blood pressure at a young adult age. Pediatr Nephrol 2010;25: 509-16.

21. Lakshmy R. Metabolic syndrome: role of maternal undernutrition and fetal programming. Rev Endocr Metab Disord 2013;14:229-40.

22. Lurbe E, Carvajal E, Torro I, et al. Influence of concurrent obesity and low birth weight on blood pressure phenotype in youth. Hypertension 2009;53:912-7.

23. Chen X, Zhang ZX, George LK, et al. Birth measurements, family history, and environmental factors associated with later-life hypertensive status. Am J Hypertens 2012;25:464-71.

24. Westerhof N, Westerhof BE. A review of methods to determine the functional arterial parameters stiffness and resistance. J Hypertens 2013;31:1769-75.

25. Stergiopulos N, Segers P, Westerhof N. Use of pulse pressure method for estimating total arterial compliance in vivo. Am J Physiol 1999;276:H424-8.

26. Bhuiyan AR, Chen W, Srinivasan SR, et al. Relationship of low birth weight to pulsatile arterial function in asymptomatic younger adults: the Bogalusa Heart Study. Am J Hypertens 2010;23:168-73.

27. Broyd C, Harrison E, Raja M, et al. Association of pulse waveform characteristics with birth weight in young adults. J Hypertens 2005;23:1391-6.

28. Doumas M, Papademetriou V, Faselis C, et al. Gender differences in hypertension: myths and reality. Curr Hypertens Rep 2013;15:321-30. 